\title{
Inoculação da bactéria Pseudomonas fluorescens no índice de crescimento da Brachiaria decumbens spp
}

\author{
Inoculation of bacteria Pseudomonas fluorescens in \\ growth indice of Brachiaria decumbens spp
}

Käthery Brennecke ${ }^{[a]}$, Liandra Maria Abaker Bertipaglia ${ }^{[a]}$, Alexandre Antoniazzi ${ }^{[b]}$, Edson Ferreira Souza ${ }^{[c]}$

[a] Professoras Doutoras do curso de mestrado em Produção Animal da Universidade Camilo Castelo Branco (UNICASTELO), Descalvado, SP, Brasil, e-mails: katherybr@yahoo.com.br, liandramab@terra.com.br

[b] Acadêmico do curso de Agronomia da Universidade Camilo Castelo Branco (UNICASTELO), Descalvado, SP, Brasil, e-mail: alexandreantoniazzi@gmail.com

[c] Acadêmico do curso de mestrado em Produção Animal da Universidade Camilo Castelo Branco (UNICASTELO), Descalvado, SP, Brasil, e-mail: edson_zooiesa@hotmail.com

\section{Resumo}

O efeito da inoculação de bactérias Pseudomonas fluorescens sobre o crescimento de gramíneas pode ser avaliado mediante análises de características morfofisiológicas das pastagens. Portanto, o objetivo foi verificar características morfofisiológicas de Brachiaria decumbens cv. Basilisk, inoculadas com Pseudomonas fluorescens, através das medidas morfométricas das plantas. 0 delineamento experimental adotado foi inteiramente casualizado, composto por três tratamentos (testemunha, inoculação na semente e inoculação via água de irrigação) com 10 repetições cada. No tratamento de inoculação na semente, as sementes ficaram imersas em $100 \mathrm{ml}$ de solução bacteriana na quantidade de 1,67 x 107 UFC/mL durante cinco minutos. Em seguida foram plantadas diretamente em 10 vasos. No tratamento inoculação via água de irrigação, as sementes foram plantadas diretamente nos vasos e receberam irrigação durante 10 dias consecutivos com 100 mL de solução bacteriana na quantidade de 1,67 x 106 UFC/mL/vaso. Após o aparecimento da terceira folha começaram as medidas intervalo de aparecimento foliar, alongamento de colmo e número de folhas por perfilho, para posterior cálculo de suas respectivas taxas. Os resultados obtidos não mostraram valores significativos para as taxas de intervalo de aparecimento foliar (IApF). Porém, foram encontrados resultados significativos para a taxa de alongamento de colmo e para o número de folhas por perfilho. Conclui-se que a inoculação com Pseudomonas fluorescens promoveu maior alongamento de colmo e maior número de folhas no perfilho, o que é desejável do ponto de vista nutricional, pois aumentou a relação folha/ colmo das plantas.

Palavras-chave: Capim-braquiária. Morfogênese. RPCPs. Rizobactérias. 


\section{Abstract}

The effect of inoculation of bacteria Pseudomonas fluorescens on the growth of grasses can be measured by analysis of morphophysiological characteristics of pastures. Therefore, the objective was to verify the morphophysiological characteristics of Brachiaria decumbens cv. Basilisk, inoculated with Pseudomonas fluorescens, measuring plant morphometrics. The experimental design was completely randomized, with three treatments (control, inoculating the seed and inoculation through irrigation water) with 10 repetitions each. In inoculating the seed treatment, seeds were immersed in $100 \mathrm{ml}$ of bacterial solution in the amount of 1,67 $x 107 \mathrm{CFU} / \mathrm{mL}$ for five minutes. Then planted directly in 10 pots. In the treatment by inoculation irrigation water, seeds were planted directly in pots was irrigated and for 10 consecutive days with $100 \mathrm{ml}$ of bacterial solution in the amount of $1,67 \times 106 \mathrm{CFU} / \mathrm{ml} /$ pot. After the appearance of the third leaf is initiated measures of leaf appearance interval, stem elongation and leaf number per tiller for subsequent calculation of their respective rates. The results show no significant values for leaf appearance interval rates (IAPF). However, significant results were found for stem elongation rate and the number of leaves per tiller. It was concluded that inoculation with Pseudomonas fluorescens promoted greater elongation of stems and more leaves on the tiller, which is desirable from a nutritional point of view, because it increased the leaf / stem ratio of plants.

Keywords: Brachiaria-grass. Morphogenesis. RPCPs. Rhizobacteria.

\section{Introdução}

Devido ao clima e dimensões territoriais favoráveis, o sistema de produção animal de bovinos no Brasil é predominantemente a pasto, sendo a melhor opção de custo e utilizada como principal fonte de alimento para os rebanhos (Mello e Pedreira, 2004).

A utilização da forragem e sua otimização, visando a produção e o desempenho animal, é o foco no manejo de pastagem, e dependem da sua produtividade e perenidade.

A produção e a perenidade da pastagem decorrem da característica da emissão contínua de folhas e perfilhos, que garantem a reconstituição da área foliar do relvado sob pastejo (Barbosa et al., 1998).

Segundo Pinto et al. (1994), a relação folha/ colmo é um importante fator no manejo e no valor nutritivo da pastagem. Wilson e t'Mannetje (1978) comentam que a alta relação folha/colmo representa forragens com alto teor de proteína, digestibilidade e consumo, além de conferir melhor adaptação e tolerância ao pastejo e ao corte.

Em condições de pastejo, o consumo animal é influenciado pela disponibilidade da forragem e também pela sua estrutura de pastagem (Rodrigues et al., 2008). Nesse sentido, o número de folhas por perfilho sugere um maior índice de área foliar, incremento na taxa de aparecimento foliar e modificação na estrutura da pastagem, e com o alongamento do colmo é esperado uma queda no valor nutritivo da pastagem.

Portanto, a análise de índices de crescimento possibilita identificar as características da planta associadas à adaptação e potencial de produção em condições favoráveis (Rodrigues et al., 2008), evidenciando a necessidade de investigação de modelos de índices de crescimento e morfofisiológicos para definições de estratégias de manejo de pastagens.

Acredita-se que uma importante estratégia consiste na inoculação das sementes de Brachiaria com bactérias promotoras de crescimento vegetal, que já possuem comprovado efeito benéfico em gramíneas. Dentre tais bactérias, a Pseudomonas fluorescens, que se destaca como potente colonizadora da rizosfera, é uma alternativa para reduzir custos e diminuir riscos ambientais causados por fertilizantes (Zucarelli et al., 2011).

Segundo Coelho (2007), a utilização destes microrganismos passou a ser uma alternativa para 
diminuição da utilização de agrotóxicos e produtos químicos que, se utilizados de forma errônea, podem atingir o lençol freático e contaminar os recursos hídricos. Além disso, o uso de tais inoculantes pode aumentar a produção agrícola, tornar o produto mais competitivo e diferenciado e ainda diminuir os custos para o produtor, pela menor necessidade de insumos.

Bolan et al. (1997) afirmam que a inoculação com Rizobactérias Promotoras de Crescimento (RPCPs) no solo é uma opção para a promoção de crescimento da planta e da solubilização de fosfatos inorgânicos, por excretarem ácidos orgânicos e colonização rizosférica, o que pode também reduzir custos com fontes de fósforo no solo.

Chanway (1997) relata que as RPCPs têm sido consideradas essenciais em relação ao suprimento de nutrientes disponibilizados às plantas, como nitrogênio, fósforo e ferro, auxiliando no melhor desenvolvimento no ciclo vegetal.

Observam-se os benefícios das RPCPs em função do crescimento e desenvolvimento de estudos com sorgo (Chiarini et al., 1998), milho (Araújo et al., 2002; Hungria et al., 2010), trigo (Luz, 2001), batata (Gasoni et al., 2001), citrus (Amorin e Melo, 2002) e soja (Hungria et al., 2005). Nesses casos, a promoção de crescimento está atrelada a vários fatores, como análise do crescimento da planta, diminuição na incidência de patógenos ou severidade de doenças, e ao aumento na produção de grãos.

0 efeito benéfico da inoculação de bactérias Pseudomonas fluorescens pode afetar diretamente a qualidade das pastagens, cuja produtividade pode ser avaliada decorrente da contínua emissão de folhas e perfilhos, que é um processo importante da restauração da área foliar sob condições de pastejo ou corte (Bircham e Hodgson, 1983).

Segundo Querioz et al. (2006) e Pedrinho (2009), os Pseudomonas fluorescens são rizobactérias que se destacam como potentes colonizadoras da rizosfera, podendo ser inoculadas no solo, aumentando o crescimento vegetal, porque produzem ou alteram a concentração de hormônios vegetais influenciando os processos fisiológicos.

Zucarelli et al. (2011) relatam que bactérias Pseudomonas fluorescens têm sido utilizadas com sucesso como promotoras de crescimento em plantas de milho. Na cultura do arroz produzem altas concentrações de citocinina, hormônio vegetal que auxilia no crescimento das plantas.

Em um experimento com gramíneas e rizobactérias, Pan et al. (1999) observaram respostas aos exsudatos das raízes de milho na produção do fitohormônio ácido indolacético (AIA), promovendo, assim, o crescimento dessa gramínea, e consideraram que tal benefício poderia ser aplicado em outras gramíneas, como as pastagens.

Os efeitos benéficos das RPCPs (Rizobactérias Promotoras de Crescimento em Plantas) podem ser observados principalmente pelo aumento da área foliar, altura da planta, diâmetro do caule, número de folhas e matéria seca, redução do tempo de aclimatação, maior sobrevivência das mudas, controle de doenças e aumento da produtividade (Mariano et al., 2004).

0 objetivo foi verificar algumas características morfofisiológicas como o intervalo de aparecimento foliar, taxa de alongamento de colmo e número de folhas por perfilho de Brachiaria decumbens cv. Basilisk, inoculadas com Pseudomonas fluorescens, via água de irrigação e na semente, através das medidas morfométricas das plantas.

\section{Material e métodos}

0 experimento foi implantado em estufa da Universidade Camilo Castelo Branco, em Descalvado (SP). 0 delineamento experimental adotado foi inteiramente casualizado, composto por 3 tratamentos (testemunha, inoculação na semente e inoculação na água de irrigação) e 10 repetições cada, totalizando 30 vasos de polietileno de $8 \mathrm{~L}$, dispostos em bancadas a $1,5 \mathrm{~m}$ do solo.

As bactérias Pseudomonas fluorescens linhagem CCMA-110 foram fornecidas pelo banco de germoplasma da Embrapa Meio Ambiente, que ficaram armazenadas em placas de petri em geladeira até o momento do uso. 0 meio de cultura utilizado foi o NA, que possui a seguinte composição: $0,5 \%$ peptona, $0,3 \%$ extrato de levedura, $1,5 \%$ de Agar e $0,5 \%$ de $\mathrm{NaCl}$ e $\mathrm{pH}$ neutro (Moretini et al., 2004). Os componentes foram pesados utilizando uma balança analítica. Foi produzido $1 \mathrm{~L}$ de meio de cultura, que foi autoclavado durante 20 minutos a $121^{\circ} \mathrm{C}$ e vertido em placas de petri. 
As bactérias foram repicadas na forma de estrias e, após a repicagem, as placas foram vedadas com filme plástico de PVC e levadas para a estufa a uma temperatura de $35 \mathrm{oC}$ durante $24 \mathrm{~h}$. Posteriormente, o recolhimento da suspensão diluída com bactérias foi efetuado de acordo com Sottero (2003).

Este procedimento foi realizado com 3 placas, e o valor final da quantidade de bactérias foi obtido através da média. Os valores médios obtidos nas placas foram: placa $1=186 \mathrm{UFC}$, placa $2=187 \mathrm{UFC}$, placa $3=128$ UFC.

Para os tratamentos na testemunha, após desinfecção 100 sementes foram submersas em $100 \mathrm{~mL}$ de água destilada.

Para o tratamento inoculação na semente, após a desinfecção, 100 sementes foram lavadas com água destilada, e em seguida as sementes ficaram imersas em $100 \mathrm{~mL}$ de suspensão bacteriana na quantidade de 1,67 x $107 \mathrm{UFC} / \mathrm{mL}$ durante 5 minutos.

E para o tratamento inoculação via água de irrigação, após desinfecção, 100 sementes foram lavadas com água destilada. Posteriormente, as sementes foram enviadas ao plantio, e a irrigação foi feita durante 10 dias consecutivos com $100 \mathrm{~mL}$ de suspensão bacteriana na quantidade de 1,67 x $106 \mathrm{UFC} / \mathrm{mL} /$ vaso (utilizando uma placa de petri a cada dia). Ao término dos 10 dias, a quantidade total de bactérias inoculadas foi de 1,67 x 107 UFC/mL/vaso (Sottero, 2003) e após 10 dias, a irrigação foi feita com $1200 \mathrm{~mL}$ de água destilada por vaso, igualmente aos outros tratamentos, nunca ultrapassando os $70 \%$ da capacidade de campo, calculado como $1200 \mathrm{~mL}$ de água por vaso.

Para a etapa do plantio, o solo foi caracterizado como sendo de textura argilosa, coletado de barranco (em perfil), nas dependências da universidade.

Foram enviadas amostras de solo para realização da análise química, a fim de se fazer as devidas correções de fertilidade e de acidez. Os resultados foram: $\mathrm{pH}=4,5$; $\mathrm{M} \cdot \mathrm{O}=13 \mathrm{~g} \cdot \mathrm{dm}^{3 ;} \mathrm{P}=16 \mathrm{mg} \cdot \mathrm{dm}^{3}$; $\mathrm{H}+\mathrm{Al}=38 \mathrm{mmol} . \mathrm{dm}^{3} ; \mathrm{K}=0,3 \mathrm{mmol} . \mathrm{dm}^{3} ; \mathrm{Ca}=16$ mmol. $\mathrm{dm}^{3} ; \mathrm{Mg}=6 \mathrm{mmol} . \mathrm{dm}^{3} ; \mathrm{SB}=22,3 \mathrm{mmol} . \mathrm{dm}^{3}$; CTC $=60,3$ mmol. $\mathrm{dm}^{3} ; \mathrm{V}=37 \%$.

A esterilização do solo foi realizada através do processo de solarização (Cruz e Silva, 2006), por um período de 40 dias (Ghini, 1997).

Posteriormente, foram enchidos 30 vasos de polietileno de $8 \mathrm{~L}$ para composição dos 3 tratamentos, com 10 repetições cada. Não houve necessidade de calagem. A adubação foi realizada de acordo com os resultados obtidos na análise de solo e as recomendações técnicas do Boletim 100.

Foram plantadas 10 sementes por vaso, e após a germinação as plantas foram raleadas, deixando cinco plantas homogêneas por vaso. Um perfilho foi marcado com arame branco para identificação da planta a ser medida. Somente após o aparecimento da terceira folha começaram as medidas alongamento de colmo, intervalo de aparecimento foliar e número de folhas por perfilho. Essas medidas foram feitas com o auxílio de uma trena de bolso de $1 \mathrm{~m}$ e as medições foram realizadas em intervalos de 48 horas, durante 45 dias.

Para os cálculos das medidas de intervalo de aparecimento foliar, taxa de alongamento de colmo foram utilizadas as seguintes fórmulas de acordo com Peternelli (2003): Intervalo de aparecimento foliar (IApF - dias.folha ${ }^{-1}$. perfilho ${ }^{-1}$ ), Taxa de alongamento de colmo (TAlC - cm.dia ${ }^{-1}$.perfilho ${ }^{-1}$ ).

Também foi avaliado o número de folhas por perfilho (folhas.perfilho ${ }^{-1}$ ) e o alongamento do colmo, do qual tomou-se por base a altura da lígula da última folha expandida em relação ao nível do solo.

A análise estatística foi realizada seguindo-se a metodologia do sistema estatístico sigma Stat, versão 2.03 , com nível de significância a $5 \%$ pelo teste de Tukey.

\section{Resultados e discussão}

Os resultados médios do intervalo de aparecimento foliar, taxa de alongamento de colmo e número médio de folhas por perfilho, por tratamento, obtidas ao longo do experimento, estão apresentados na Tabela 1 .

Para o intervalo de aparecimento foliar não foram encontradas diferenças estatísticas significativas entre os tratamentos.

Dados sobre a inoculação de Pseudomonas fluorescens em Brachiarias, como referência ao crescimento e produção, são escassos na literatura, e os dados encontrados na literatura em função do IApF são diversos por se tratar de uma variável que é influenciada por inúmeros fatores internos, 
relacionados à própria fisiologia da planta, e por fatores externos, do ambiente.

Tabela 1 - Resultados médios dos valores de índice de aparecimento foliar (IApF) (dias.folha-1. .perfilho $^{-1}$ ) por tratamento, obtidos ao longo do experimento

\begin{tabular}{|c|c|c|c|}
\hline Tratamentos & $\begin{array}{c}\text { Intervalo de } \\
\text { Aparecimento } \\
\text { Foliar (dias) }\end{array}$ & $\begin{array}{c}\text { Taxa de } \\
\text { alongamento } \\
\text { do colmo (cm) }\end{array}$ & $\begin{array}{c}\text { Folhas por } \\
\text { perfilho } \\
\text { (n) }\end{array}$ \\
\hline Testemunha & $3,77 \pm 0,49 \mathrm{a}$ & $1,48 \pm 0,36 \mathrm{~b}$ & $9,78 \pm 0,76 \mathrm{~b}$ \\
\hline Irrigação & $4,04 \pm 0,30 \mathrm{a}$ & $1,63 \pm 0,30 \mathrm{ab}$ & $10,52 \pm 0,42 \mathrm{a}$ \\
\hline Semente & $3,65 \pm 0,38 \mathrm{a}$ & $1,85 \pm 0,31 \mathrm{a}$ & $10,13 \pm 0,55 \mathrm{a}$ \\
\hline
\end{tabular}

Nota: Médias seguidas da mesma letra na coluna não diferem entre si pelo teste de Tukey, a $5 \%$ de probabilidade.

Paciullo et al. (2007), avaliando o crescimento de Brachiaria decumbens nas quatro estações do ano, em sistemas silvipastoris, encontraram valores de intervalos médios de aparecimento foliar de 8 dias. folha $^{-1}$. perfilho $^{-1}$ no verão.

Gonçalves (2002), trabalhando com regimes de lotação em pastos, observou que a estação do ano exerce influência sobre o intervalo de aparecimento foliar. Em novembro encontrou os menores intervalos de aparecimento foliar $\left(7,4\right.$ dias.folha ${ }^{-1}$. perfilho $^{-1}$ ) e em fevereiro, o valor máximo (13 dias. folha ${ }^{-1}$.perfilho-1).

Sbrissia e Silva (2001) comentam que o alongamento do colmo interfere no comprimento final da folha e, sobretudo, na relação folha/colmo do pasto, portanto essa característica deve ser analisada para o entendimento dos processos de fluxos de tecidos em gramíneas tropicais.

Segundo Curcelli (2009), o alongamento de colmo é reconhecidamente importante em gramíneas tropicais. Em plantas tropicais e subtropicais, o alongamento do colmo assume maior importância relativa como característica morfogênica, determinando variáveis estruturais do dossel como a relação folha/colmo. Os resultados médios encontrados de alongamento de colmo no presente experimento podem ser observados na Tabela 1.

Os maiores valores de alongamento do colmo foram encontrados no tratamento de inoculação de Pseudomonas fluorescens na semente, porém, sem diferenças significativas se comparado com o tratamento de inoculação via irrigação. Em relação à testemunha, o tratamento de inoculação via irrigação obteve um acréscimo de 10,1\%. 0 tratamento de inoculação via semente diferiu estatisticamente, com um acréscimo de $25 \%$ comparado com a testemunha.

Campos et al. (2007), analisando características morfogênicas e estruturais da Brachiaria decumbens em sistema silvipastoril e cultivo exclusivo, encontraram valores de alongamento de colmo variando de acordo com a condição solar recebida $\mathrm{x}$ estação do ano. Maiores valores foram encontrados na condição de sombreamento intenso, enquanto que a sol pleno houve diferença entre as estações do ano, cujo valor foi maior no verão $(1,4 \mathrm{~cm})$.

De acordo com Santos (2007), o número de folhas por perfilho (folhas.perfilho-1) é uma variável importante em termos quantitativos da planta, pois interfere diretamente na relação folha/ colmo. As folhas das forragens são a principal fonte de alimento para os ruminantes criados a pasto. Os valores médios do número de folhas por perfilho estão apresentados na Tabela 1.

Observa-se que o maior número de folhas por perfilho foi produzido pelos tratamentos onde a inoculação da Pseudomonas fluorescens ocorreu via água de irrigação e na semente, apresentando diferenças significativas quando comparados com o tratamento testemunha, discordando dos relatos de Misaghi (1990) e de Zucarelli et al. (2011) ao afirmarem que rizobactérias em gramíneas não promovem crescimento vegetal.

Santos et al. (2011), avaliando a influência das variações naturais da planta no mesmo pasto sobre as características morfogênicas e estruturais da Brachiaria decumbens, manejada sob lotação contínua com bovinos, observaram que o número de folhas não é modificado pela altura da planta.

Segundo Lemaire e Chapman (1996), o número de folhas vivas por perfilho, apesar de determinado geneticamente, pode variar com as condições de meio e de manejo da pastagem; é uma característica genotípica estável na ausência de deficiências hídricas e nutricionais. Portanto, a ocorrência do número constante de folhas por perfilho pode resultar de condições de meio insuficientes para modificar esta variável. 


\section{Conclusão}

Concluiu-se que a bactéria Pseudomonas fluorescens promoveu o incremento das taxas de alongamento de colmo e do número de folhas por perfilho, características desejáveis do ponto de vista nutricional, porquanto aumentou a relação folha/ colmo da planta.

\section{Referências}

Amorim EPR, Melo IS. Ação antagônica de rizobactérias contra Phytophthora parasítica e p. citropthora e seu efeito no desenvolvimento de plântulas de citrus. Rev Bras Frutic. 2002;24(2):565-8.

Araújo WL, Marcon J, Maccheroni Jr W, Van ELsas JD, Van Vuurde JWL, Azevedo JL. Diversity of endophytic bacterial populations and their interaction with Xilella fastidiosa in citrus plants. Appl Environ Microbiol. 2002;68(10):4906-14.

Barbosa MAAF, Cecato U, Beraldo JA, Yanaka FY, Onorato WM, Peternelli M, et al. Comportamento de perfilhamento do capim mombaça (Panicum maximum Jacq. cv. Mombaça). Reunião Anual da Sociedade Brasileira de Zootecnia, 35; 1998; Botucatu. Botucatu: Sociedade Brasileira de Zootecnia; 1998.

Bircham JS, Hodgson J. The influence sward conditions on rates of herbage growth and senescence in mixed swards under continuous stocking management. Grass Forage Sci. 1983;38(4):323-31.

Bolan NS, Elliot J, Gregg PEH, Weil S. Enhanced dissolution of phosphate rocks in the rhizosphere. Biol Fertil Soils. 1997;24:169-74.

Campos NR, Paciullo DSC, Bonaparte TP, Guimarães Netto MM, Carvalho RB, Tavela RC, et al. Características morfogênicas e estruturais de Brachiaria decumbens em sistema silvipastoril e cultivo exclusivo. R Bras Bioci. 2007;5(Supl. 2):819-21.

Chanway CP. Inoculation of tree roots with plant growth promoting soil bactéria: na emerging technology for reflorestation. Forest Sci. 1997;43(1):99-112.
Coelho LF, Freitas SS, Melo AMT, Ambrosano GB. Interação de bactérias fluorescentes do gênero Pseudomonas e de Bacillus spp. com a rizosfera de diferentes plantas. R Bras Cienc Solo. 2007;31(6):1413-20.

Corsi M, Balsamore MA, Santos PM. Bases para o estabelecimento do manejo de pastagem de braquiária. Simpósio sobre manejo da pastagem; 1994; Piracicaba. Piracicaba: Fundação de Estudos Agrários Luíz de Queiróz; 1994.

Costa MP. Efeito da matéria orgânica em alguns atributos do solo [dissertação]. Piracicaba: Escola Superior Luíz de Queiroz, USP; 1983. 137 p.

Cruz JCS, Silva MA. Solarização de solos, uma opção para o manejo de culturas na agricultura familiar. Pesquisa \& Tecnologia. 2006;3(1).

Curcelli F. Respostas morfogênicas e dinâmica de acúmulo de forragem do capim xaraés [ Brachiaria brizantha (A. Rich) Stapf. Cv. Xaraés] submetido a estratégias de pastejo rotativo [dissertação]. Piracicaba: Universidade de São Paulo; 2009. 90 p.

Ghini R. Desinfestação do solo com o uso de energia solar: solarização e coletor solar. Ernbrapa-CNPMA. Circular, 1. Jaguariúna: Embrapa-CNPMA; 1997. 29 p.

Gomide JA, Gomide CAM. Fundamentos e estratégia do manejo de pastagens. I Simpósio de Produção de Gado de Corte; 1997; Viçosa. Viçosa: UFV; 1997.

Gonçalves AC. Características morfogênicas e padrões de desfolhação em pastos de capim - Marandu submetidos a regimes de lotação contínua [dissertação]. Piracicaba: Escola Superior de Agricultura "Luiz de Queiroz", Universidade de São Paulo; 2002. 124 p.

Hungria M, Campo RJ, Souza EM, Pedrosa FO. Inoculation with selected strains of Azospirillum brasiliense and a lipoferum improve yelds of maize and wheat in Brazil. Plant Soil. Dordrecht. 2010;331(1):413-25.

Hungria M, Franchini JC, Campo RJ, Graham PH. The importance of nitrogen fixation to soybean cropping in South America. In: Werner D, Newton W (Eds.). Nitrogen fixation in agriculture, forestry, ecology and the 
enviromental. Dordrecht: Springer; 2005. p. 25-42.

Lemaire G, Chapman D. Tissue flows in grazed plant communities. In: Hodgson J, Illius AW. (Eds.). The ecology and management of grazing systems. Guildford: Cab International; 1996. p. 3-36.

Luz WC. Evaluation of plant growth-promoting and bioprotecting rhizobacteria on wheat crop. Fitopatol Bras. 2001;26(3):597-600.

Machado JM. Morfogênese de gramíneas nativas sob níveis de adubação nitrogenada [dissertação]. Santa Maria: Universidade Federal de Santa Maria; 2010. 78 p.

Mariano RLR, Silveira EB, Assis SMP, Gomes AMA, Nascimento ARP, Donato VMTS. Importância de bactérias promotoras de crescimento e de biocontrole de doenças de plantas para uma agricultura sustentável. Anais da Academia Pernambucana de Ciência Agronômica, Recife. 2004;1:89-111.

Mello ACL, Pedreira CGS. Respostas morfológicas do capim Tanzânia (Panicum maximum cv. Tanzânia) irrigado à intensidade de desfolha sob lotação rotacionada. R Bras Zootec. 2004;33(2):282-9.

Misaghi IJ. Screening bacteria for root colonizing ability by a rapid method. Soil Biol Biochem. 1990;22(8):1085-8.

Moretini A, Spessoto AN, Melo IS. Fungicida Metalaxil na microbiota e na atividade enzimática do solo. Pesticidas: R Ecotoxicol e Meio Ambiente. 2004;14:73-84.

Paciullo DSC, Carvalho CAB, Aroeira LJM, Morenz MF, Lopes FCF, Rossiello ROP. Morfofisiologia e valor nutritivo do capim-braquiária sob sombreamento natural e a sol pleno. Pesq Agropec Bras. 2007;42(4):573-9.

Pan B, Bay YM, Leibovitch S, Smith DL. Plant-growth promoting rhizobacteria and kinetin as ways to promote corn growth and yield in a short growing season area. Eur J Agron. 1999;11(3-4):179-86.

Pedrinho EAN. Isolamento e caracterização de bactérias promotoras de crescimento em milho [dissertação]. Jaboticabal: Faculdade de Ciências Agrárias e Veterinárias UNESP; 2009. 74 p.
Peternelli M. Características morfogênicas e estruturais do capim-braquiarão [Brachiaria brizantha (Hochst ex A. Rich) Stapf. cv. Marandu] sob intensidades de pastejo [dissertação]. Pirassununga: Faculdade de Zootecnia e Engenharia de Alimentos, USP; 2003. 79 p.

Pinto JC, Gomide JÁ, Maestri M. Produção de matéria seca e relação folha/caule de gramíneas forrageiras tropicais, cultivadas em vasos, com duas doses de nitrogênio. Rev Bras Zootec. 1994;23(3):313-26.

Queiróz BPV, Aguilar-Vildoso CI, Melo IS. Visualização in vitro da colonização de raízes por rizobactérias. Summa Phytopathol. 2006;32(1):95-7.

Raij BVAN, Cantarella H, Quaggio JA, Furlani AMC (Ed.). Recomendações de adubação e calagem para o Estado de São Paulo. 2 ed. Campinas: IAC; 1996. 285 p. (IAC. Boletim Técnico, 100).

Rodrigues RC, Mourão GB, Brennecke K, Luz PHC, Herling VR. Produção de massa seca, relação folha/colmo e alguns índices de crescimento do Brachiaria brizantha cv. Xaraés cultivado com a combinação de doses de nitrogênio e potássio. R Bras Zootec. 2008;37(3):394-400.

Santos LC. Morfogênese, características estruturais e produtivas de braquiárias com diferentes adubações [dissertação]. Itapetinga: Universidade Estadual do Sudoeste da Bahia; 2007. 62 p.

Santos MER, Fonseca DM, Braz TGS, Silva SP, Gomes VM, Silva GP. Características morfogênicas e estruturais de perfilhos de capim braquiária em locais do pasto com alturas variáveis. R Bras Zootec. 2011;40(3):535-42.

Sbrissia AF, Silva SC. O ecossistema de pastagens e a produção animal. Reunião anual da Sociedade Brasileira de Zootecnia, 38; 2001; Piracicaba: SBZ; 2001. p. 731-54.

Silva SC, Corsi M. Manejo do pastejo. Simpósio sobre manejo da pastagem; 2003; Piracicaba. Piracicaba: Fundação de Estudos Agrários Luiz de Queiróz; 2003.

Sottero AN. Colonização radicular e promoção de crescimento vegetal por rizobactérias [dissertação]. Campinas: Instituto Agronômico; 2003. 61 p. 
Wilson JR, t'Mannetje L. Senescence, digestibility and carbohydrate content of buffel gran and green panic leaves in swards. Aust J Agric Res. 1978;29:503-19.

Zucarelli C, Cil IR, Prete CEC, Prando AM. Eficiência agronômica da inoculação à base de Pseudomonas fluorescens na cultura do milho. Revista Agrarian. 2011;4: 152-7.

Recebido em: 24/05/2016

Received in: 05/24/2016

Aprovado em: 15/12/2016

Approved in: 12/15/2016 